\title{
Modulation of redox homeostasis under suboptimal conditions by Arabidopsis nudix hydrolase 7
}

\author{
Niranjani Jambunathan ${ }^{1}$, Anuradha Penaganti ${ }^{1}$, Yuhong Tang ${ }^{2}$, Ramamurthy Mahalingam ${ }^{1 *}$
}

\begin{abstract}
Background: Nudix hydrolases play a key role in maintaining cellular homeostasis by hydrolyzing various nuceloside diphosphate derivatives and capped mRNAs. Several independent studies have demonstrated that Arabidopsis nudix hydrolase 7 (AtNUDT7) hydrolyzes NADH and ADP-ribose. Loss of function Atnudt7-1 mutant plants (SALK_046441) exhibit stunted growth, higher levels of reactive oxygen species, enhanced resistance to pathogens. However, using the same T-DNA line, two other groups reported that mutant plants do not exhibit any visible phenotypes. In this study we analyze plausible factors that account for differences in the observed phenotypes in Atnudt7. Secondly, we evaluate the biochemical and molecular consequences of increased NADH levels due to loss of function of AtNUDT7 in Arabidopsis.

Results: We identified a novel conditional phenotype of Atnudt7-1 knockout plants that was contingent upon nutrient composition of potting mix. In nutrient-rich Metro-Mix, there were no phenotypic differences between mutant and wild-type (WT) plants. In the nutrient-poor mix (12 parts vermiculite: 3 parts Redi-earth and 1 part sand), mutant plants showed the characteristic stunted phenotype. Compared with WT plants, levels of glutathione, $\mathrm{NAD}^{+}, \mathrm{NADH}$, and in turn NADH:NAD${ }^{+}$ratio were higher in Atnudt7-1 plants growing in 12:3:1 potting mix. Infiltrating NADH and ADP-ribose into WT leaves was sufficient to induce AtNUDT7 protein. Constitutive overexpression of AtNudt7 did not alter NADH levels or resistance to pathogens. Transcriptome analysis identified nearly 700 genes differentially expressed in the Atnudt7-1 mutant compared to WT plants grown in 12:3:1 potting mix. In the Atnudt7-1 mutant, genes associated with defense response, proteolytic activities, and systemic acquired resistance were upregulated, while gene ontologies for transcription and phytohormone signaling were downregulated.

Conclusions: Based on these observations, we conclude that the differences observed in growth phenotypes of the Atnudt7-1 knockout mutants can be due to differences in the nutrient composition of potting mix. Our data suggests AtNUDT7 plays an important role in maintaining redox homeostasis, particularly for maintaining NADH: $\mathrm{NAD}^{+}$balance for normal growth and development. During stress conditions, rapid induction of AtNUDT7 is important for regulating the activation of stress/defense signaling and cell death pathways.
\end{abstract}

\section{Background}

Pyridine nucleotides (PNs), which include $\mathrm{NAD}^{+}, \mathrm{NADP}^{+}$, $\mathrm{NADH}$ and $\mathrm{NADPH}$, are ubiquitous coenzymes involved in redox reactions in all organisms [1,2]. In plants, PNs act as developmental cues during the process of seed germination [3] and for transitioning from the vegetative to

\footnotetext{
* Correspondence: ramamurthy.mahalingam@okstate.edu

1246 Noble Research Center, Department of Biochemistry and Molecular

Biology, Oklahoma State University, Stillwater, Oklahoma, USA

Full list of author information is available at the end of the article
}

reproductive state [4]. Levels of PNs in plants are altered by light conditions and age of plants [5]. Changes in PN level in response to abiotic stresses like chilling and drought or in response to fungal elicitors and pathogens have also been reported [6-9]. Recently, it has been shown that extracellular PNs induce pathogenesis-related (PR) gene expression and disease resistance pathways in Arabidopsis [10]. Thus, PN homeostasis impacts several developmental and stress signaling pathways in plants.

\section{(Ciomed Central}


Several studies in animal systems have shown that the ratio of oxidized to reduced form of PNs, especially $\mathrm{NAD}^{+}: \mathrm{NADH}$, acts as an important signal that connects metabolic states of the cell to its gene expression pattern [11-13]. Cellular PN levels, or more importantly, redox states, are sensed by repressors of gene expression, which in turn regulate chromatin architecture $[11,14]$. However, the enzymes regulating PN levels and in turn its impact on gene expression have not been well studied in plants.

Nudix (nucleoside diphosphates linked to moiety X) hydrolases play a vital role in cellular homeostasis by catalyzing the hydrolysis of a variety of nucleoside diphosphate derivatives including $\mathrm{NADH}, \mathrm{NAD}^{+}, \mathrm{ADP}-$ ribose, NTPs, dNTPs, phosphoinositol derivatives, and capped mRNAs [15]. Since these substrates have regulatory roles or may be toxic, nudix hydrolases play a key role in signaling and house-cleaning processes. There are 29 nudix hydrolases identified in Arabidopsis thaliana [16]. In vitro enzymatic analyses have been carried out for nine cytosolic nudix hydrolases of Arabidopsis [17]. The first characterized plant nudix hydrolase, AtNUDT1, was NADH pyrophosphatase [18]. AtNUDT1 was later shown to be the canonical mutT-type nudix hydrolase in Arabidopsis, important for scavenging oxidized nucleotides, especially deoxyguanosines [19]. Recently, it was shown that over-expression of AtNUDT2, an ADP-ribose pyrophosphatase, confers enhanced tolerance to oxidative stress [20]. This enhanced tolerance was attributed to maintenance of NAD and ATP levels by nucleotide recycling from free ADP-ribose under stress conditions [20]. Several independent research groups have analyzed various aspects of Arabidopsis nudix hydrolase 7 (AtNudt7) [6,17,20-25]. In vitro analysis demonstrated that AtNUDT7 could use both NADH and ADP-ribose as substrates [6,17,23,24]. Over-expression of AtNudt7 ( $P_{35 s}$ : AtNUDT7) led to a decrease in both NADH and ADP-ribose levels, whereas in a T-DNA knockout line, Atnudt7-1, (SALK_046441), the levels of these two metabolites were higher than wild-type (WT) plants grown under the same conditions, suggesting that both NADH and ADP-ribose are physiological substrates of this protein [22].

The knockout Arabidopsis mutant, Atnudt7-1, which was previously referred to as growth factor gene 1 (gfg1), has been described as having pleiotropic phenotypes such as reduced size, higher levels of reactive oxygen species (ROS), microscopic cell death, constitutive expression of pathogenesis-related (PR) genes, and improved resistance to a virulent bacterial pathogen, Pseudomonas syringae DC3000 [23]. Both Atnudt7-1 and an independent T-DNA knockout line, Atnudt7-2 (SALK_104293), were reported to exhibit reduced size, higher levels of salicylic acid, and increased resistance to an oomycete pathogen, Hyaloperonospora parasitica [26]. Another independent group demonstrated constitutive PR gene expression, increased resistance to a virulent bacterial pathogen, and reduced hypersensitive response to avirulent bacterial pathogens (P syringae Avrrpt2 and P glycinea Avrrpt2) in Atnudt7-1 mutant [21]. However, two other groups using the Atnudt7-1 line reported no differences in the growth or morphology of mutant plants under normal growing conditions [6].

This contradiction in reported Atnudt7-1 phenotype combined with similar observations in our laboratory prompted us to examine this mutant more carefully. In this study, we describe a conditional growth phenotype of Atnudt7-1 that is influenced by edaphic factors. Mutant plants were reduced in size when grown in nutrient-poor mix of vermiculite: Redi-earth: sand (12:3:1), but grew to the same size as WT plants when raised on nutrient-rich Metro-Mix (MM). Higher levels of AtNUDT7 protein were observed when WT plants were grown in 12:3:1 mix and under several abiotic and biotic stress conditions culminating in cell death. Interestingly, increased $\mathrm{NADH}$ was observed in Atnudt7-1 only under suboptimal growing conditions. Affymetrix gene chip analysis of Atnudt7-1 mutants grown under suboptimal conditions showed substantial changes in gene expression. Genes associated with systemic acquired resistance (SAR) and cell death pathways were induced in the mutant. Down regulation of several hormone-signaling pathways in the mutant indicated interconnections between $\mathrm{PN}$ homeostasis and phytohormones. These results demonstrate that AtNUDT7 plays a crucial role in regulating NAD ${ }^{+}$: NADH balance under suboptimal conditions, which in turn modulates the activation of defense, phytohormones and cell death signaling pathways.

\section{Results}

\section{Atnudt7-1 mutant exhibits a conditional phenotype}

We observed that the type of potting mix influenced the phenotype of Atnudt7-1 mutant. The typical stunted growth phenotype of Atnudt7-1 was observed consistently when plants were raised in 12:3:1 potting mix. Atnudt7-1 mutant plants in Metro-Mix 200 (MM) were the same size as WT plants (Fig. 1A and Fig. 1B). In the 12:3:1 potting mix, growth of WT Col-0 was comparable to the plants in MM for 3-4 weeks (Fig. 1A and Fig. 1B). We analyzed the nutrient composition of both mixes (Table 1). The 12:3:1 potting mix had low levels of all tested macro- and micronutrients. In some cases, the levels of these nutrients were lower than the optimum range recommended. These data suggested that the phenotype of Atnudt7-1 was strongly influenced by the microenvironment in which these plants were growing. 


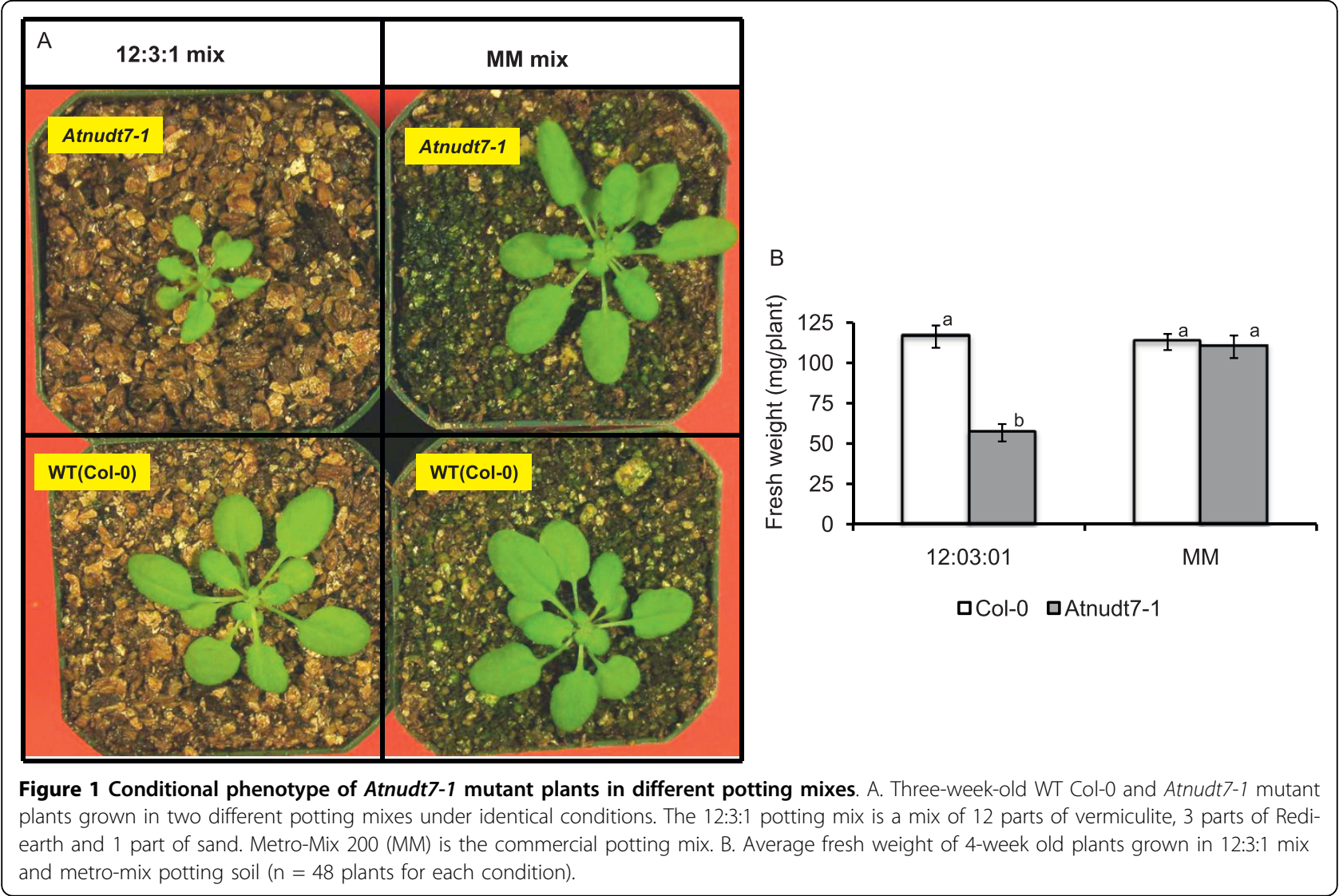

Supplementing individual nutrients (N, P, K, Ca, and $\mathrm{Mg}$ ) in 12:3:1 potting mix to the levels observed in $\mathrm{MM}$ improved the growth habit of the mutant plants. However, compared with WT plants the mutant plants were still smaller in size (data not shown). Irrigating the mutant plants in 12:3:1 potting mix with a commercial fertilizer solution restored the WT phenotype with respect to size or biomass.

Atnudt7-1 grown in 12:3:1 mix showed reduced growth of virulent bacterial pathogen $P$. syringae

Table 1 Nutrient analysis of the potting mixes used for growing Atnudt7-1 plants

\begin{tabular}{lll}
\hline & $\mathbf{1 2 : 3 : 1 ~} \mathbf{~ m i x}$ & Metro-Mix 200 \\
\hline Nitrate-N (ppm) & 14 & 68 \\
Potassium (ppm) & 25 & 241 \\
Phosphorus (ppm) & 3.5 & 42.6 \\
Calcium (ppm) & 93 & 290 \\
Magnesium (ppm) & 19 & 324 \\
Ammonium-N (ppm) & 0.4 & 0.6 \\
Iron (ppm) & 11.8 & 24.4 \\
Zinc (ppm) & 1.4 & 3.2 \\
Copper (ppm) & 2.7 & 4.1 \\
Sulfate (ppm) & 300 & 1043 \\
Boron (ppm) & 0.1 & 0.3 \\
\hline
\end{tabular}

pathovar tomato (DC3000), indicating enhanced resistance of these plants to pathogens $[6,21,23,26]$ (Fig. 2). When Atnudt7-1 plants were grown in MM the increased resistance to $P$. syringae was compromised (Fig. 2).

\section{AtNudt7 is upregulated in plants grown under suboptimal conditions}

AtNUDT7 protein shares close sequence homology to AtNUDT2 and AtNUDT6 [26]. In vitro assays indicate AtNUDT7 has affinity for ADP-ribose and NADH, the preferred substrates for AtNUDT2 and AtNUDT6 [17]. We monitored the transcriptional profiles levels of these three nudix hydrolase genes under different growth conditions. Steady-state transcript levels of $A t N u d t 2$ and AtNudt6 did not show any difference in Col-0 plants grown in the two different potting mixes. Compared to plants in $\mathrm{MM}$ a 2-fold up regulation of $A t N u d t 7$ transcripts was observed in plants grown in 12:3:1 mix (Fig. 3A).

Induction of AtNUDT7 protein was also observed in WT Col-0 plants grown in 12:3:1 mix (Fig. 3B). Accumulation of AtNudt7 transcripts and protein under nutrient deficient growing conditions in WT plants suggests that this protein may play an important role under these situations. 


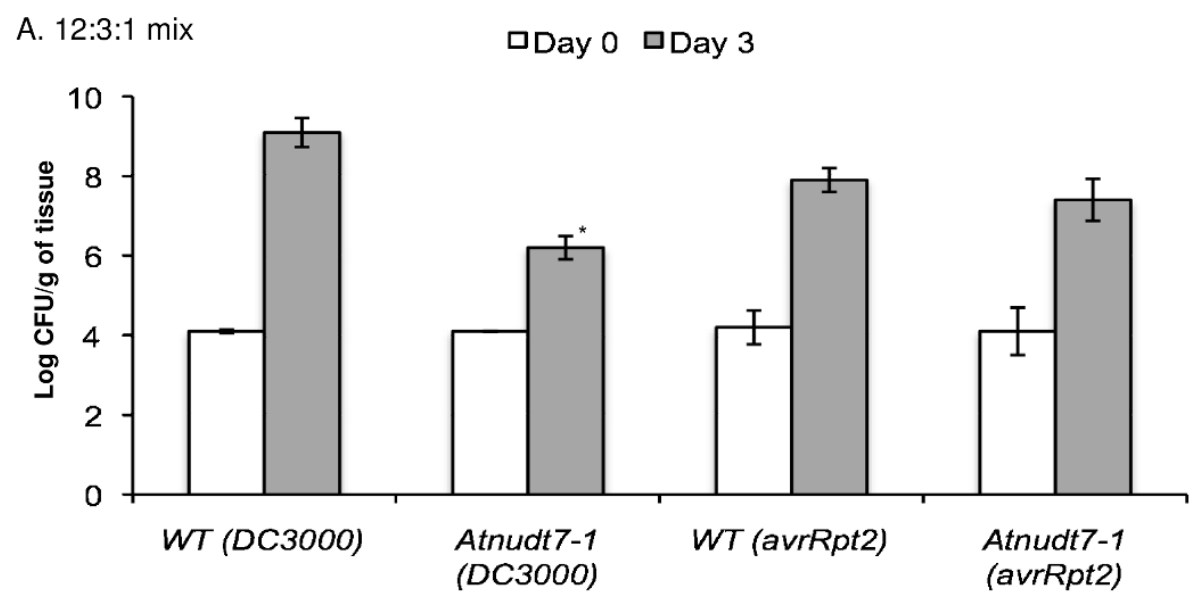

B. Metro-mix $\quad$ aDay 0 aDay 3

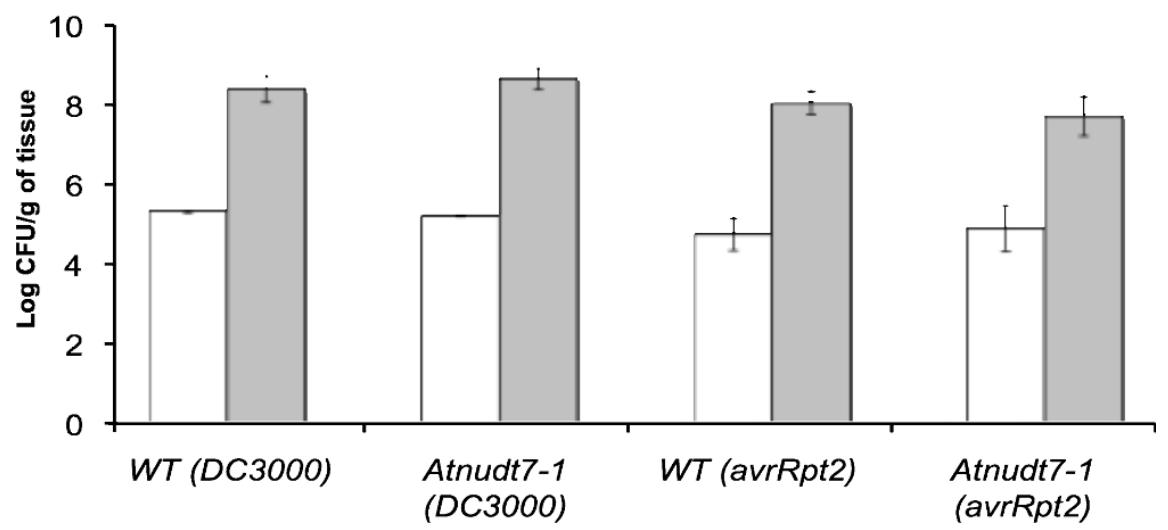

Figure 2 In planta growth of Pseudomonas syringae in WT Col-0 and Atnudt7-1 plants raised on Metro-Mix. Growth of virulent $P$ syringae DC3000 and avirulent $P$ syringae DC3000 containing Avrrpt2 were monitored on the day of infiltration and three days after infiltration. Error bars represent average of 3 replicates \pm SD. CFU stands for colony forming units.

\section{AtNUDT7 protein levels are induced in response to} biotic and abiotic stresses

We monitored AtNUDT7 protein accumulation in Col-0 WT plants after infiltrating leaves with Pseudomonas syringae pathovar tomato (avrRpt2) bacterial pathogen, which induces the hypersensitive cell death response. AtNUDT7 protein levels had accumulated to high levels by four hours of pathogen treatment (Fig. 4A). Similarly, rapid accumulation of AtNUDT7 was observed after two hours of acute ozone treatment in the ozone sensitive Ws-0 ecotype (Fig. 4B). We also observed that AtNUDT7 protein levels were induced within eight hours of wounding by a sharp blade (Fig. 4C). These data clearly demonstrated rapid induction of AtNUDT7 protein during both biotic and abiotic stress treatments that culminate in cell death.
Over-expressing AtNUDT7 does not alter PN levels but alters expression of closely related nudix hydrolases Transgenic plants (T2 generation) that over-express AtNUDT7 under the control of constitutive cauliflower mosaic $35 \mathrm{~S}$ promoter $\left(P_{35 s}: A t N u d t 7\right)$ were generated in the WT Col-0 background and confirmed by western analysis using AtNUDT7 polyclonal antibodies (Fig. 5A). The $P_{35 s}$ :AtNudt7 plants were similar to $\mathrm{WT}$ in size in both MM and 12:3:1 mix. $P_{35 s}:$ AtNudt7 plants infiltrated with $P$. syringae DC3000 did not show any differences in pathogen growth compared with WT plants (Additional file 1, Fig. S1). Levels of NAD and NADH did not change in Pro $_{35 S}$ :AtNudt7 plants when compared with the vector control or with WT Col-0 plants grown in MM or 12:3:1 mix (Additional file 1, Fig. S1). Another group over-expressing the AtNudt7 gene under the control of $35 \mathrm{~S}$ promoter reported similar results [6]. 


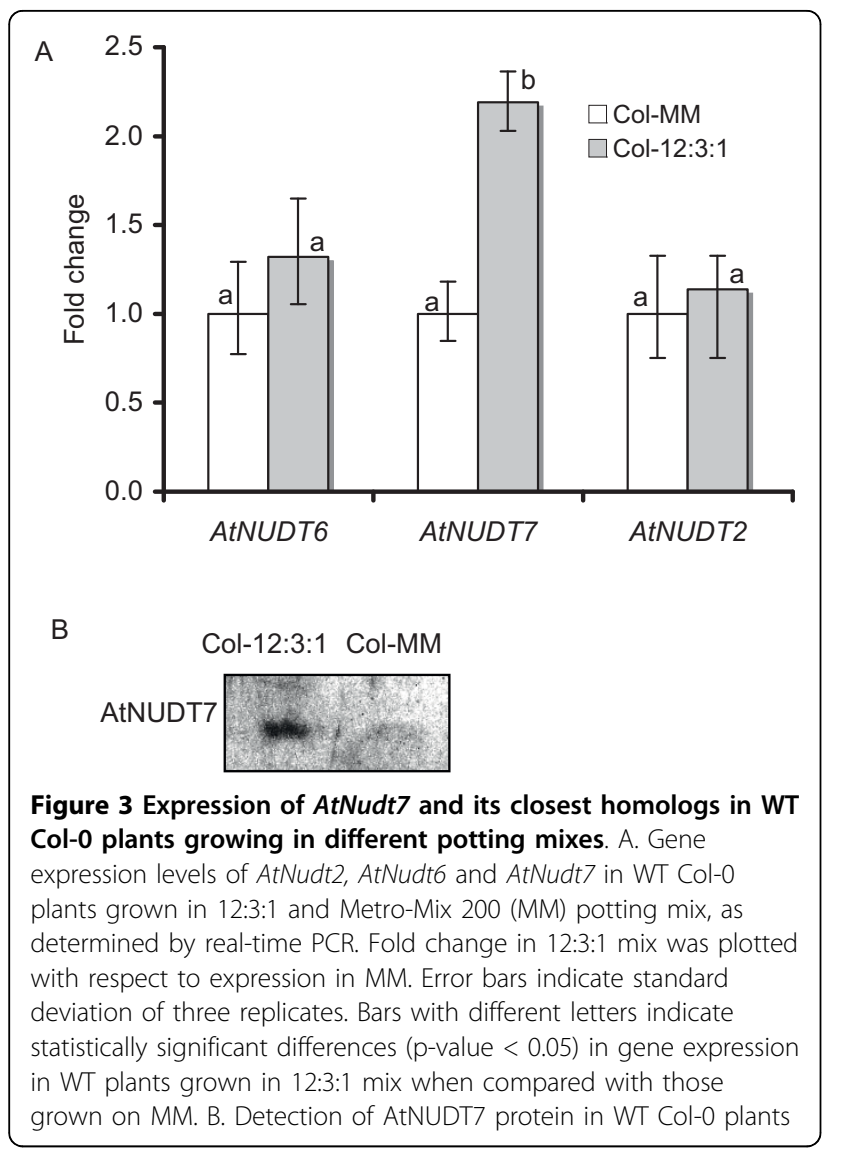

Using real-time PCR, we monitored the expression levels of the closest homologs of AtNudt7 in overexpressor lines and compared them to those of the Atnudt7-1 mutant and WT plants (Fig. 5B). Expression of AtNudt6 and AtNudt10 genes was higher in $P_{35 s}$ : AtNudt7 plants than WT. Interestingly, AtNudt6 was also highly expressed in Atnudt7-1 mutant plants. The expression of $A t N u d t 2$ was not altered in the $P_{35 s}$ : AtNudt7 and Atnudt7-1 plants.

\section{Induction of AtNUDT7 protein is triggered by its substrates}

Exogenous application of NADH or ADP-ribose to WT plants led to a substantial increase in AtNUDT7 protein levels when compared to control plants infiltrated with water (Fig. 6). Based on these observations, we speculate that NADH and ADP-ribose are likely physiological substrates for AtNUDT7 or these metabolites may confer stability to this protein.

\section{Redox perturbations under suboptimal conditions are plausible triggers for inducing AtNUDT7 protein}

Glutathione levels were higher in Atnudt7-1 mutant plants than WT plants grown under similar conditions, which was again consistent with an earlier study [6]. Differences in glutathione levels in WT plants grown in the two different potting mixes were not significant (Fig. 7A).

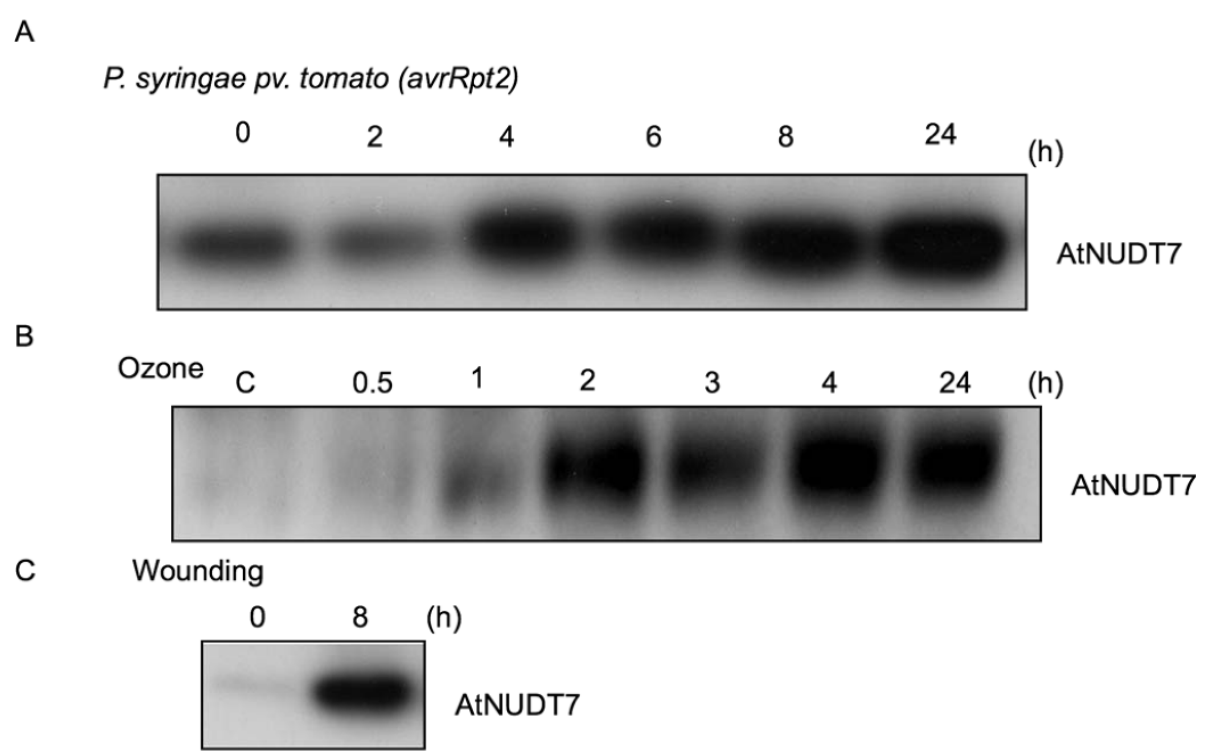

Figure 4 Western analysis using polyclonal antibodies raised against recombinant AtNUDT7 protein. A. WT Col-0 plants were infected with $1 \times 10^{6} \mathrm{CFU} / \mathrm{mL}$ of Pseudomonas syringae avrRpt2. Leaves were harvested immediately after infiltration (0), and at 2, 4, 6, 8, and 24 hours post-infection For each lane, $20 \mu \mathrm{g}$ of total protein was used. B. Three-week old Wassilewskija ecotype plants were fumigated with $250 \mathrm{~nL}$. $\mathrm{L}^{-1}$ of ozone for six hours. Rosettes were collected at 0.5, 1, 2, 3, and 4 hours during ozone treatment and 24 hours after the initiation of treatment. Control (C) plants were maintained under ambient ozone conditions. For each lane, $20 \mu \mathrm{g}$ of total protein was used. C. AtNUDT7 protein levels were monitored in WT Col-0 plants eight hours after wounding by a sharp blade. For each lane, $20 \mu \mathrm{g}$ of total protein was used. 
A

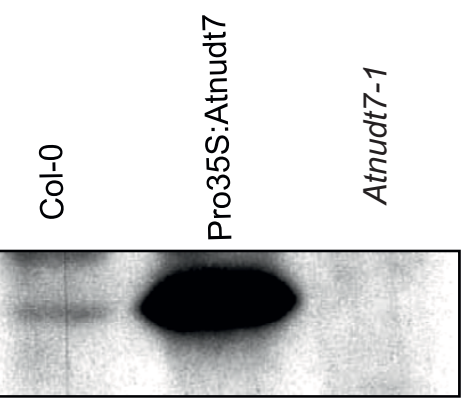

AtNUDT7

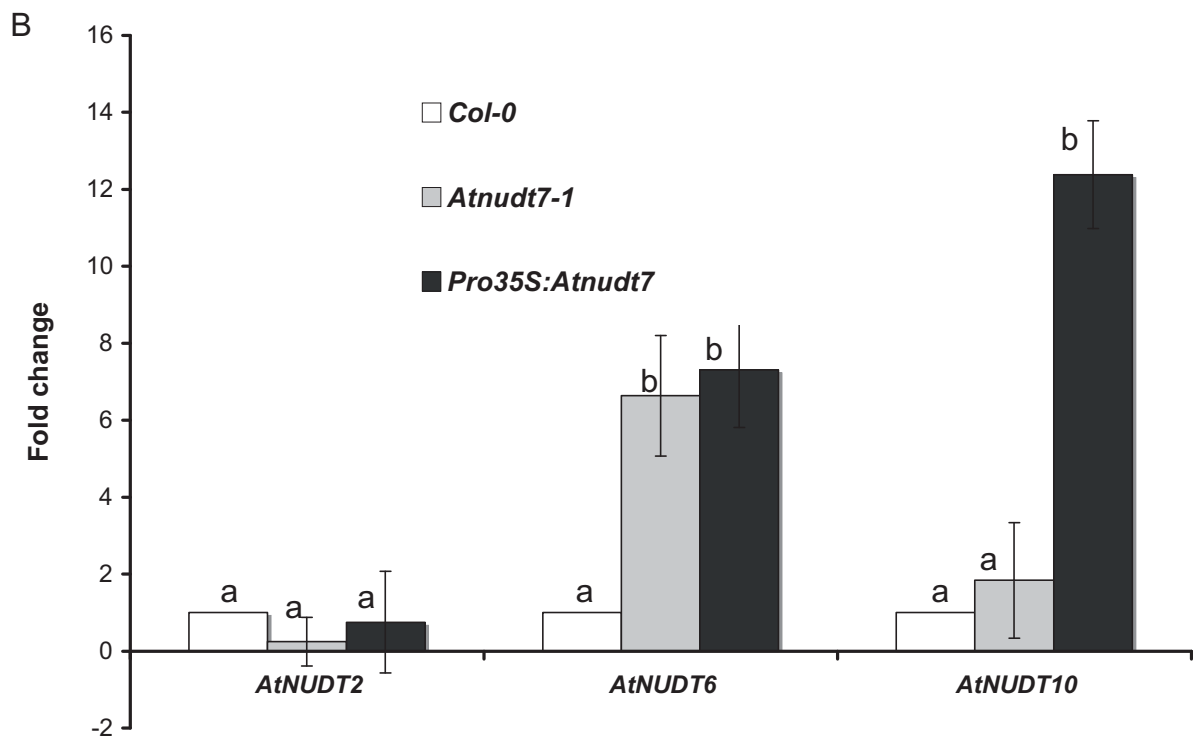

Figure 5 Analysis of $P_{35 s}:$ AtNudt7 transgenic lines in Col-0 background. A. AtNUDT7 protein levels in Col-0, Pro $355:$ AtNudt7 transgenic lines and Atnudt7-1 mutant plants based on western blot analysis with anti-NUDT7 antiserum. B. Expression of AtNUDT2, AtNUDT6 and AtNUDT10 genes in Col-0, Pro 355 :AtNUDT7 and Atnudt7-1 mutant plants by real-time PCR analyses. Error bars indicate standard deviation of three replicates. Bars with different letters indicate statistically significant differences in gene expression when compared with the corresponding WT.

Amount of ascorbate (AsA) and dehydroascorbate (DHA) were similar in WT and Atnudt7-1 plants grown in MM. AsA levels in Atnudt7-1 mutant growing in 12:3:1 potting mix were comparable to those observed in MM. Interestingly, we observed nearly $30 \%$ decrease in the AsA levels of WT plants grown in 12:3:1 mix

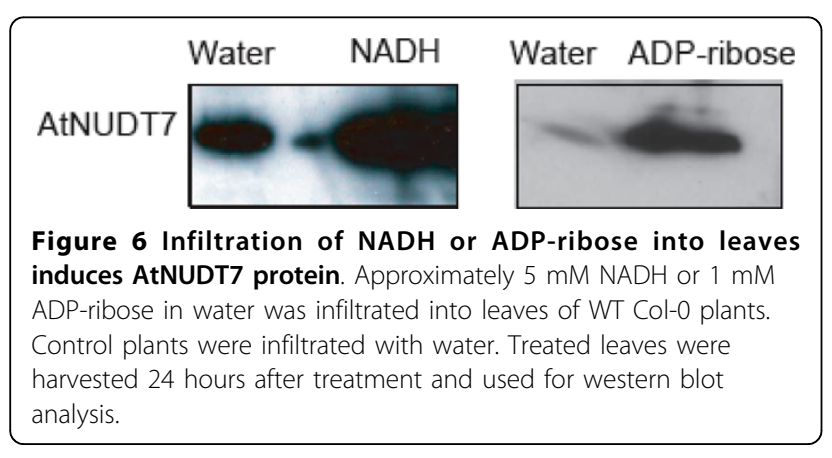

(Fig. 7B). Furthermore, DHA levels were almost undetectable in the WT plants growing in 12:3:1 mix. This indicated that differences in potting mix caused significant changes in AsA/DHA redox couple in WT plants, even though their consequences did not manifest phenotypically.

Comparison of $\mathrm{NAD}^{+}$levels in WT and Atnudt7-1 plants growing in MM or in 12:3:1 mix did not show any significant differences (Fig. 7C). NAD+ levels in plants growing in 12:3:1 mix was higher than in plants growing in MM but was not statistically significant for Atnudt7-1. Atnudt7-1 plants in 12:3:1 mix showed almost 2-fold higher levels of NADH than WT plants (Fig. 7D). In contrast, Atnudt7-1 plants in MM did not show any change in NADH levels compared to WT plants grown under identical conditions. The observed increase in $\mathrm{NAD}^{+}$and NADH levels in Atnudt7-1 plants growing in 12:3:1 mix manifested as higher NADH: 


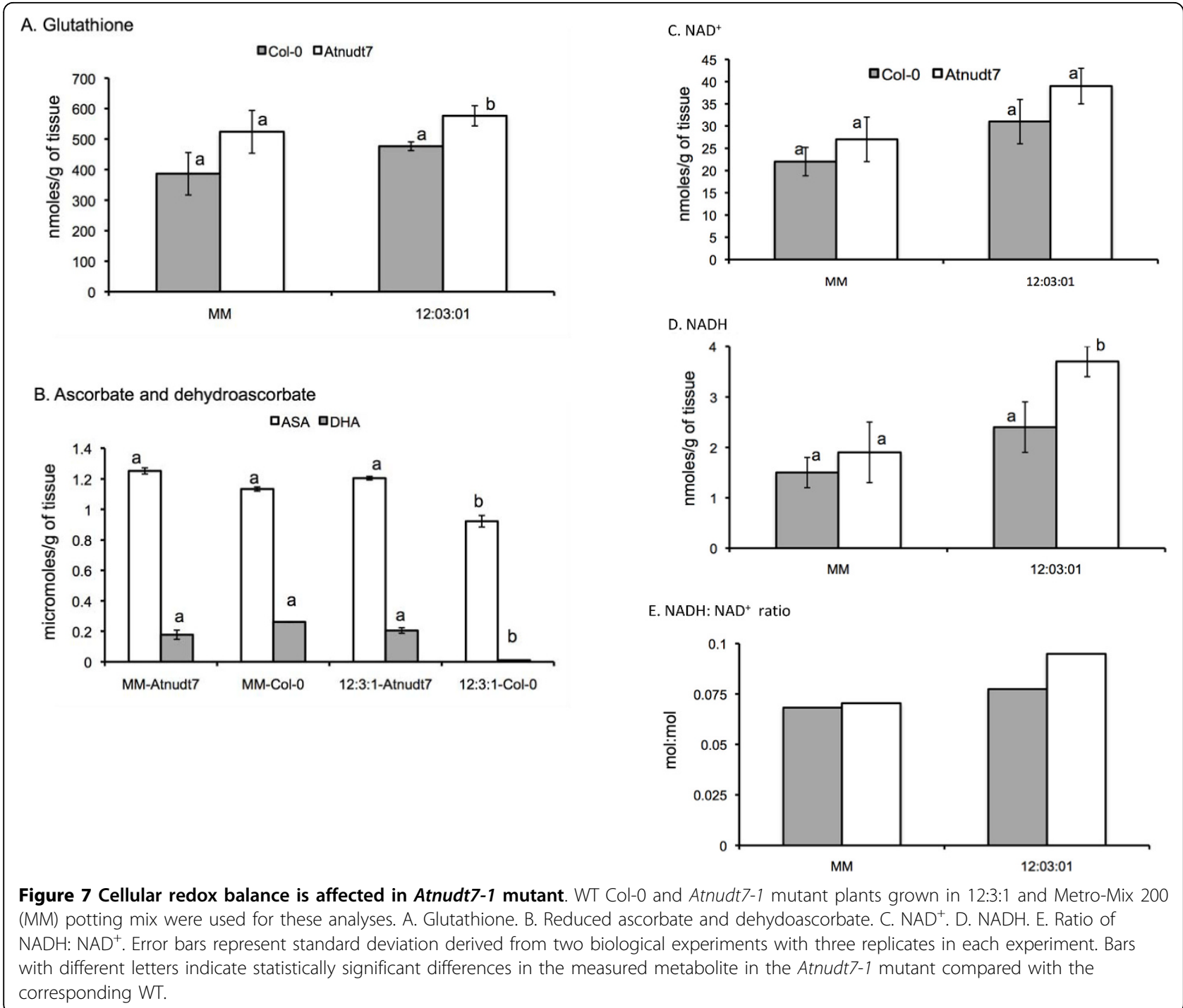

$\mathrm{NAD}^{+}$ratios when compared to plants growing in $\mathrm{MM}$ (Fig. 7E). These data showed that alterations in growth conditions including nutrient status impact NADH: $\mathrm{NAD}^{+}$ratios in plants, and lack of AtNUDT7 protein exaggerated the changes in this redox couple.

\section{Substantial changes in gene expression in Atnudt7-1 plants grown under suboptimal conditions}

Based on studies in animal systems, we speculated that higher levels of NADH and GSH in Atnudt7-1 plants under suboptimal conditions might bring about changes in gene expression. Arabidopsis ATH1 gene chips with 22,500 probe sets representing 24,000 genes were used to examine changes in transcript levels in Atnudt7-1 plants with respect to expression observed in WT controls grown in 12:3:1 mix. Experiments were conducted with 3-week-old plants since the phenotype of the mutant plants was distinct at this stage of development when grown in 12:3:1 potting mix. Based on two biological replications of the Genechip experiments $\left(R^{2}=\right.$ $0.98), 1607$ genes were reliably detected in the WT versus Atnudt7-1 comparison. There were 396 genes that were 2 -fold induced and 470 genes that were 2 -fold repressed (Additional file 2, Table S1). Thus, under suboptimal growing conditions, lack of AtNUDT7 protein resulted in extensive changes in gene expression.

To gain insight into the biological significance of the genes differentially expressed in Atnudt7-1, we used MAPMAN analysis [27]. The overrepresented gene ontologies are presented in Table 2. Marked changes in the expression of genes regulating transcription, protein degradation, signaling, redox and phytohormones were seen in the Atnudt7-1 mutant (Fig. 8). The majority of the transcription factor encoding genes (37) was 
Table 2 Overrepresented gene ontologies in Atnudt7-1 mutant in comparison with WT plants grown in 12:3:1 potting mix as determined by MAPMAN software

\begin{tabular}{ll}
\hline GO category & p-value \\
\hline Secondary metabolism-flavonoids & 0.002 \\
Signaling-receptor kinases & 0.002 \\
Biotic stress & 0.005 \\
Regulation of transcription & 0.015 \\
Unknown & 0.033 \\
Hormone metabolism-ethylene & 0.038 \\
Protein degradation & 0.043 \\
\hline
\end{tabular}

repressed, while those induced belonged to the WRKY family. The enrichment of GO for transcription among the repressed genes is supportive of the role of PNs as global metabolic regulators of gene expression [28]. Identification of a large set of genes induced in response to biotic stress provides a molecular basis for the increased resistance to pathogens reported for Atnudt7-1
$[6,23]$. Four different thioredoxin genes were upregulated while four of the five differentially expressed glutaredoxins were down regulated (Fig. 8), suggesting that the redox network is perturbed, perhaps due to imbalances in the redox input elements. Down regulation of ethylene, auxin, jasmonate responsive genes and ABA biosynthesis genes were observed in Atnudt7-1 mutant. A gene encoding isochorismate synthase, important for salicylic acid (SA) biosynthesis [29], was up regulated, which may account for reported increase in SA levels in the Atnudt7-1 mutant [26].

The observed enrichment of genes involved in proteolysis led us to examine the total protease activity in the mutant plants. Protein extracts from Atnudt7-1 leaves exhibited significantly higher protease activity using azocasein as substrate, providing biochemical corroboration for the microarray data (Fig. 9A). Addition of phenylmethanesulfonyl chloride, an inhibitor of Ser proteases and papain family cysteine proteases [30], or leupeptin, an inhibitor of cysteine proteases, reduced protease

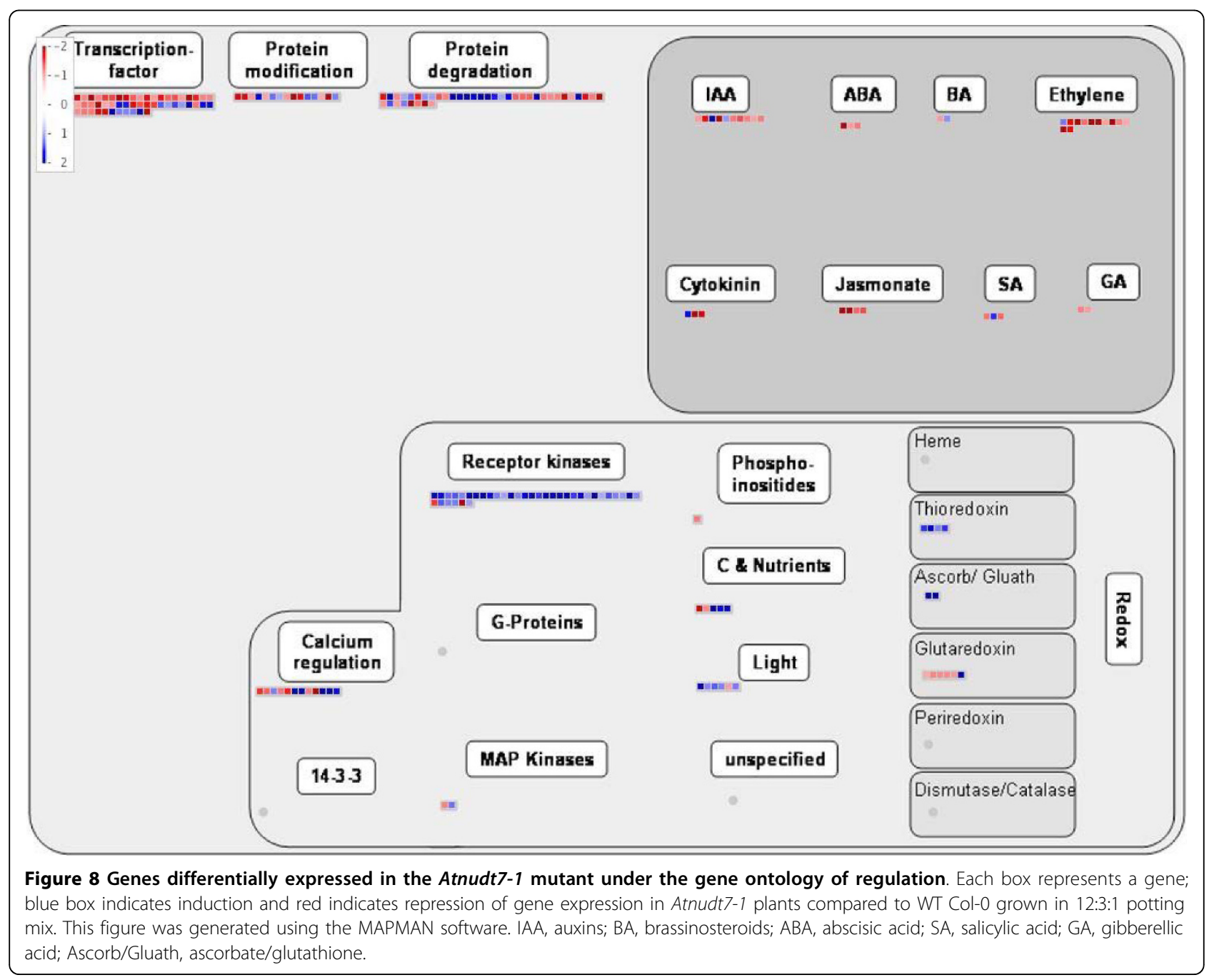




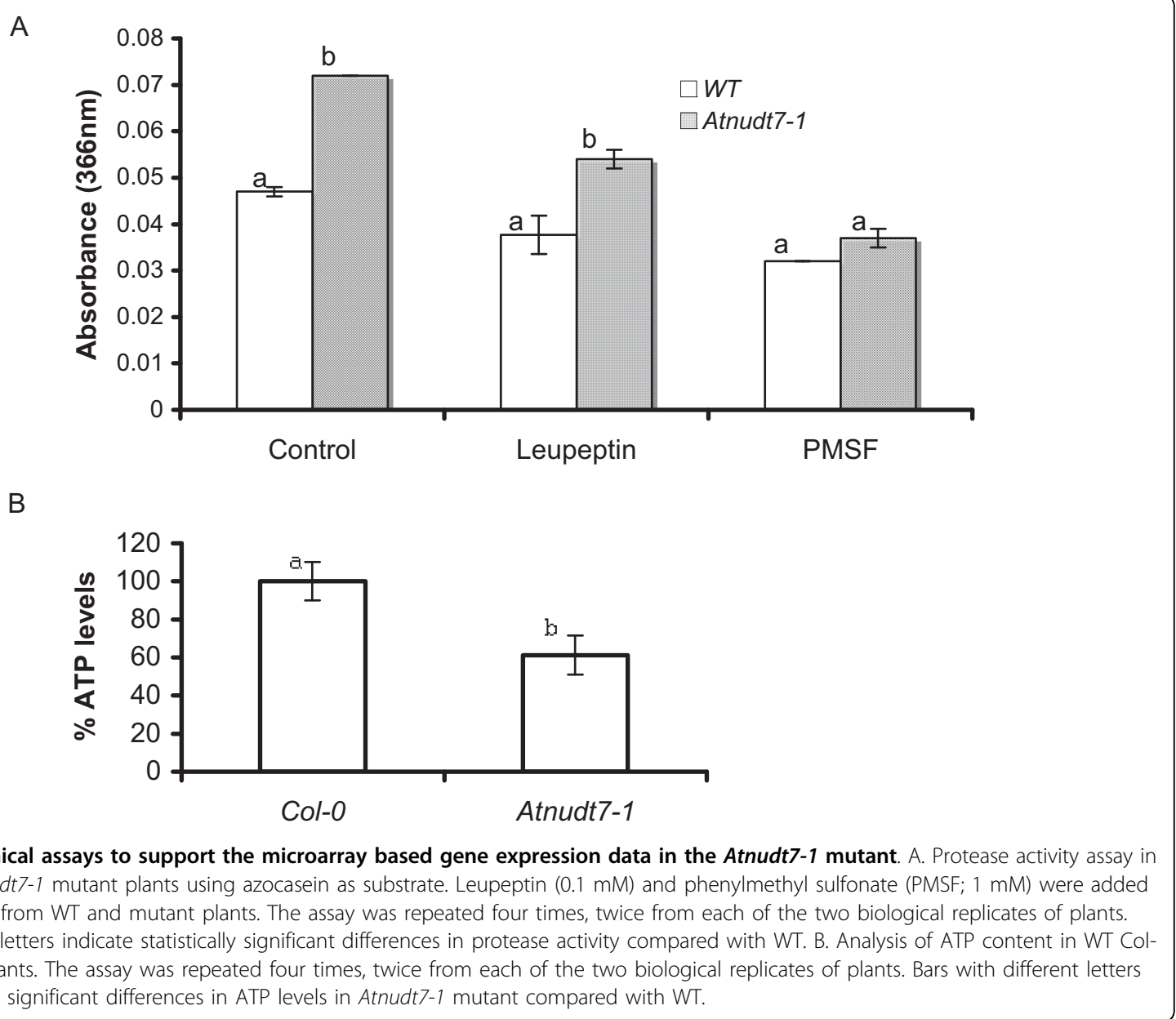

activity in both Atnudt7-1 and WT plants. There was a significant reduction in protease activity in Atnudt7-1 plant extracts after the addition of PMSF, indicating that serine proteases contributed most to the proteolytic activity.

The induction of signaling genes, especially receptorlike kinases (RLKs) in the Atnudt7-1 mutant, is intriguing (Additional file 3, Fig. S2). This observation suggested that changes in NAD: NADH balance maybe sufficient to activate a number of RLKs important for transducing signals to downstream mediators. The significant reduction in the ATP levels of Atnudt7-1 mutant suggests energy metabolism is compromised when PN balance is perturbed (Fig. 9B). The reported increases in SA levels and the gamut of phytohormone responsive genes and redox transmitters that are altered in the Atnudt7-1 mutant in conjunction with the observed changes in $\mathrm{NAD}^{+}$, NADH, GSH and ascorbate, suggests novel interconnections between redox signaling, antioxidative systems and phytohormone-mediated oxidative cell death pathways [31] (Fig. 10).

\section{Discussion}

In this study, we report a conditional phenotypic response to an edaphic factor in Atnudt7-1 mutant plants (Fig. 1). In the two earlier reports indicating that Atnudt7-1 did not show any obvious phenotypes, mutant plants were grown in soil that was fertilized [6] or were grown on nutrient rich MS plates [22]. Loss of stunted growth phenotype in Atnudt7-1 plants grown in nutrient rich metro-mix is consistent with these earlier reports. Restoration of WT phenotype in the Atnudt7-1 plants grown in 12:3:1 mix supplemented with fertilizers demonstrated that this mutant is hyper-responsive to the growth micro-environment.

Poor nutrient levels of 12:3:1 mix (Table 1) were sufficient to induce AtNUDT7 protein in WT plants, indicating that expression of this protein is important under such suboptimal conditions (Fig. 3). This is supported by strong and rapid accumulation of AtNUDT7 protein under conditions of pathogen, wounding and ozone stress (Fig. 4). Although the transcript levels of AtNudt7 showed only transient induction for a few hours 


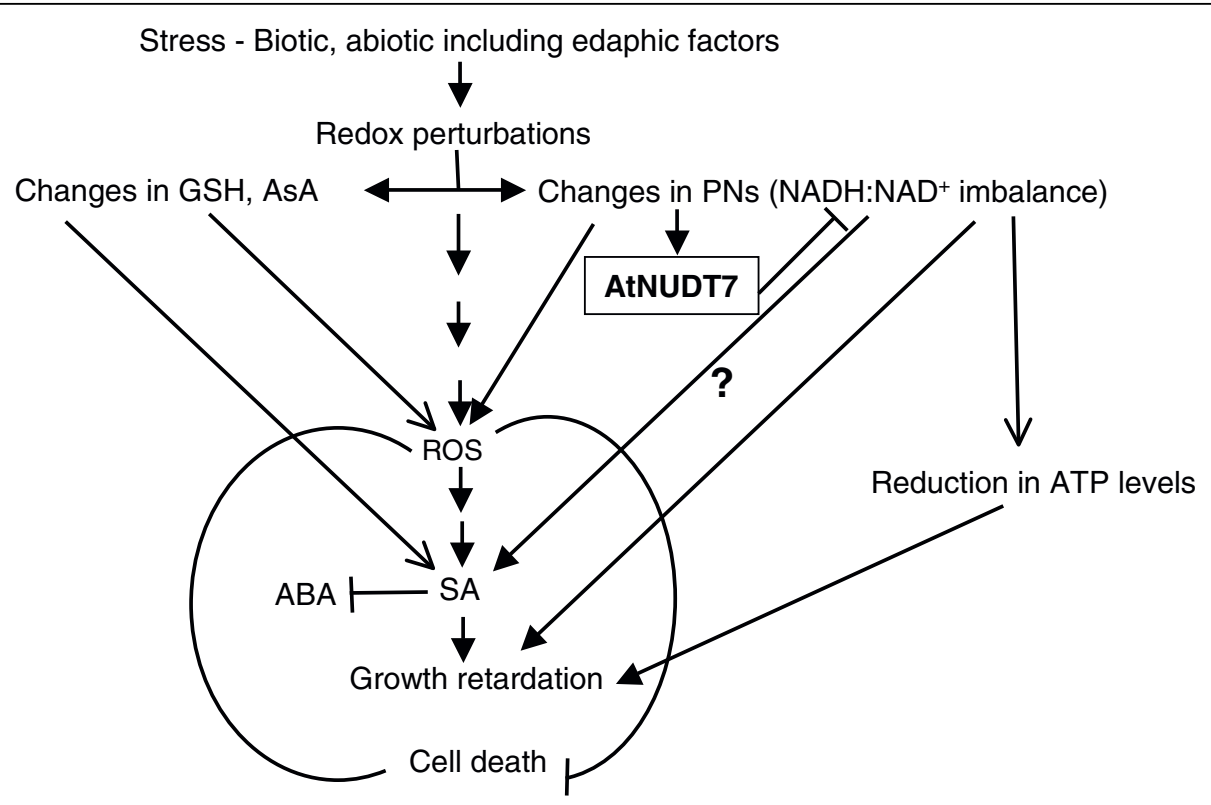

Figure 10 Working model for AtNUDT7 protein, linking redox and oxidative cell death cycles. Biotic and abiotic stresses including suboptimal growing conditions lead to alterations in ascorbate, GSH and PNs. Changes in NADH induces AtNUDT7 and maybe crucial to restore the balance of NAD ${ }^{+} \mathrm{NADH}$ redox couple. In the absence of AtNUDT7 protein, NADH levels increase and trigger the accumulation of SA by an unknown mechanism and activate the SAR pathway, which in turn can antagonize ABA signaling. SA accumulation can trigger cell death via ROS, which in turn can inhibit the cell death promotive SA signal. Reduction in ATP levels in Atnudt7-1 may be due to constitutive activation of defense/stress signaling that in turn may lead to growth retardation.

following stress treatments [23], the protein was stable for 24 hours (Fig. 4A-C). The half-life prediction of 30 hours for AtNUDT7 by the ProtParam program of ExPASy supports this observation. It is also possible that some posttranslational modification could confer stability to the AtNUDT7 protein.

Lack of AtNUDT7 protein resulted in elevated resistance to bacterial and oomycete pathogens $[6,21,23,26]$. However, our studies showed that the resistance to pathogens was compromised when Atnudt7-1 mutants were raised in MM potting soil (Fig. 2). Over expression of AtNUDT7 protein in WT plants did not alter their phenotype nor alter growth of virulent and avirulent P. syringae pathogens (Additional file 1, Fig. S1). Based on these observations, we argue that the increased resistance to pathogens observed in Atnudt7-1 plants is an indirect effect of the mutation.

Over-expression of AtNUDT7 led to elevated transcript levels of closely related nudix hydrolases (Fig. 5) suggesting coordinate regulation of members of this gene family or regulation via the substrates on which these enzymes act. Microarray data comparing Atnudt71 and WT plants indicated transcript levels of several nudix hydrolases were altered. This included AtNudt5 and $A t N u d t 6$ that were induced, while expression of AtNudt8, AtNudt17 and AtNudt24 were repressed (Additional file 2, Table S1). In the light of these observations, we caution that analysis of pyrophosphohydrolase activities in transgenic lines overexpressing or silencing particular nudix hydrolases may be misleading. In vitro studies of AtNUDT7 have revealed that this protein has significant pyrophosphohydrolase activity with NADH and ADP-ribose [17,23,24], and has recently been confirmed using transgenic lines [22]. Inducibility of AtNUDT7 protein by NADH and ADPribose provides indirect evidence that these metabolites may be its physiological substrates (Fig. 6). However, the primary biochemical function of nudix hydrolase may not be the hydrolysis of its substrates [6]. It may be involved only in conformational change as demonstrated for LTRP2, a nudix box containing protein, important for mediating calcium influx to trigger immune responses in animal immunocytes [32,33].

Atnudt7-1 mutant in 12:3:1 potting mix had 2-fold higher levels of NADH than WT plants grown under the same conditions (Fig. 7). In the male-sterile CMSI mutant of Nicotiana sylvestris, deficient in the mitochondrial complex I, levels of $\mathrm{NAD}^{+}$and $\mathrm{NADH}$ were 2-fold higher than WT plants [34] and interestingly these plants showed growth retardation similar to Atnudt7 mutant. Interestingly, increase in NADH levels did not cause changes in ROS levels in CMSII mutant but lead to reorchestration of antioxidative mechanisms resulting in higher tolerance to ozone and viral 
infections [35]. In another Arabidopsis mutant deficient in cytosolic glycerol-3-phosphate dehydrogenase (gpdhc1), increases in NADH levels and in turn the $\mathrm{NADH}: \mathrm{NAD}^{+}$ratio led to enhanced ROS levels under standard growing conditions and significantly augmented $\mathrm{H}_{2} \mathrm{O}_{2}$ production under stress [36,37]. Higher levels of NADH were reported in Atnudt7-1 mutants six hours after infection with $P$. syringae (Avrrpt2) pathogen [6]. In protein analysis experiments following $P$. syringae (Avrrpt2) pathogen infection, we observed strong induction of AtNUDT7 protein at a comparable time point (Fig. 4). This suggests under pathogen-imposed stress conditions NADH levels increase and AtNUDT7 may be required to restore $\mathrm{NAD}^{+}: \mathrm{NADH}$ balance. Such changes in $\mathrm{NAD}^{+}$and $\mathrm{NADH}$ levels during stress can lead to redox imbalance, triggering the production of ROS via one-electron reduction of oxygen $[8,36,38]$ or may be important for orchestrating cellular antioxidant systems [35]. The higher ROS levels observed in Atnudt7-1 [23,26] may be causally connected to the increase in NADH and/or NADH: $\mathrm{NAD}^{+}$.

In the Atnudt7-1 mutants exhibiting reduced size phenotype, levels of SA were reported to be 4- to 5 -fold higher than WT [26]. Several other SA-overproducing mutants have also been reported to exhibit a growth retardation phenotype [39]. The role of SA in SAR against pathogens is well known [40-42]. Furthermore, SA and ROS induce each other and form a feed-forward self-amplifying loop [43-45]. The observed increase in ROS levels in the Atnudt7-1 mutant could be due to increased levels of SA.

This begs the question - why are SA levels high in the Atnudt7-1 mutant? We speculate that an increase in SA levels may be brought about in response to redox perturbations. A positive correlation between an increase in SA levels and a corresponding increase in GSH levels using constitutive SA accumulating mutants, as well as by exogenous application of these metabolites, has been reported [46]. Increasing the levels of GSH by transgenic approaches or chemical intervention was sufficient to mimic induction of SA response genes [47-49]. The earlier reported increases in SA [26] and observed increases in GSH (Fig. 7) in Atnudt7-1 are consistent with the aforementioned studies. Recently, it was reported that exogenous application of $\mathrm{NAD}(\mathrm{P})$ induced pathogenesis-related genes and resistance to $P$. syringae maculicola, as well as accumulation of SA [10]. It is tempting to speculate that increased NADH levels or redox perturbations caused by changes in NADH:NAD ${ }^{+}$favoring the reductant, trigger the production and/or accumulation of physiologically coupled SA, GSH and ROS in Atnudt71 plants, that in turn leads to the observed pleiotropic phenotypes.
One of the other pleiotropic phenotype associated with Atnudt7-1 is microscopic cell death [23,26]. The observed constitutive activation of proteolysis-associated genes in microarray analysis (Additional file 2, Table S1) and confirmation of enhanced proteolytic activity in Atnudt7-1 plant extracts (Fig. 9A) provides a plausible explanation for the cell death phenotype. We speculate that the cell death phenotype is a manifestation of the interplay between the phytohormones, ROS and proteolysis related genes [50].

PNs are key redox input elements in the regulatory thiol-disulfide network [51] and have important roles in pro-oxidant and antioxidant metabolism [52]. PNs have also been observed to play major roles in non-redox mechanisms that influence cell function. $\operatorname{NAD}(\mathrm{H})$ is considered a key modulator of cellular energy metabolism [53,54]. Significant reduction in ATP levels of Atnudt7-1 mutant supports these earlier observations (Fig. 9B). Several lines of evidence in animal systems suggest that $\mathrm{NAD}(\mathrm{H})$ also mediates cell death [55-57], calcium homeostasis $[1,54]$ and gene expression $[14,58]$. Substantial transcriptome alterations (especially the down regulation of GO category transcription) observed in Atnudt7-1 plants are in agreement with reports in the animal literature (Fig. 8). Changes in PNs and GSH can also play an important role in gene regulation via components such as Non-Expressor of PR1 (NPR1) protein $[59,60]$.

Antagonistic cross-talk occurs at multiple levels between the SA-mediated signaling of the SAR pathway and the ABA-mediated responses to abiotic stress [61]. Microarray analysis revealed that several abiotic stress signaling pathways were down regulated, in the Atnudt7-1 mutant. This is in agreement with reports of antagonistic interactions between the SA-mediated defense in response to pathogens and ABA signaling pathways $[62,63]$.

\section{Conclusions}

Constitutive expression of AtNUDT7 under normal growing conditions is important for maintaining $\mathrm{NAD}^{+}$: NADH homeostasis. Stress, in the form of nutrient deficiency, pathogens, wounding or ozone, causes rapid and transient alterations in AtNUDT7 protein levels that can in turn alter the redox balance. These redox perturbations are important for coordinating changes in signaling pathways, including those of phytohormones, ROS, antioxidants and cell death. The mechanisms leading to an increase in SA levels due to changes in PN levels are currently unknown. It has been suggested that sporadic cell death can lead to leakage of PNs to the extracellular space, which can trigger SA biosynthesis and downstream defense signaling [10]. This increase in SA then leads to a buildup of ROS in a feed-forward 
self-amplifying loop, leading to an activated SAR pathway. Activation of SAR in turn leads to down regulation of abiotic stress signaling pathway mediated by ABA. Induced ROS can serve as a cue to suppress SA promotive signal in the propagation of cell death [64]. However, the sporadic cell death in the Atnudt7-1 mutant did not lead to confluent lesions supporting the notion that AtNUDT7 normally restricts initiation rather than propagation of cell death [26]. Based on our studies, it is clear that AtNUDT7 is an important player linking redox metabolism and oxidative stress signaling (Fig. 10). Understanding the regulation of AtNUDT7 expression will facilitate the identification of transcription factors crucial for redox homeostasis in plants both during normal growth and under stress conditions.

\section{Methods}

\section{Plant materials}

Seeds of WT, transgenic ( $\left.P_{35 s}: A t N u d t 7\right)$, and mutant (Atnudt7-1) lines were stratified in $0.1 \%$ Phytagel (Caisson Laboratories) at $4^{\circ} \mathrm{C}$ for 3 days. Seeds were sown in pots containing either a mixture of 12 parts vermiculite, 3 parts Redi-earth (composition: 55-65\% sphagnum peat moss, vermiculite, dolomitic lime; Sun Gro Horticulture) and 1 part sand (12:3:1) or Metro-Mix 200 (MM) potting mix (Scotts) for 4 weeks in a growth chamber. Plants were maintained at $22^{\circ} \mathrm{C}, 45 \%$ relative humidity, $100 \mu \mathrm{mol} \mathrm{m} \mathrm{m}^{-2} \mathrm{~s}^{-1}$ light intensity and $10 \mathrm{~h}$ day and $14 \mathrm{~h}$ dark conditions. Plants were irrigated using tap water. About 12-15 entire rosettes were harvested, flash-frozen in liquid nitrogen and stored at $-80^{\circ} \mathrm{C}$ prior to RNA extraction. Two independently grown and harvested sets of samples were used for RNA extraction and hybridization.

\section{Promoter ${ }_{355}:$ AtNudt7 overexpressor plants}

To construct transgenic plants over expressing AtNudt7, the full-length coding sequence of AtNudt7 cDNA was amplified by RT-PCR. For cloning purposes, $\mathrm{XbaI}$ and $\mathrm{BamHI}$ sites were introduced at the $5^{\prime}$ end of the forward primer (5'-CTAGTCTAGAATGGGTACTAGAGCTCAGCA-3') and the $3^{\prime}$ end of the reverse primer (5'-CGCGGATCCTCAGAGAGAAGCAGAGGCTTG-3') (restriction sites highlighted in bold), respectively. The amplified fragment was cloned into pGEM $\mathrm{T}$ vector and sequenced from both directions using universal primers to ensure that sequences were free of mutations. The insert was isolated by restriction digestion and cloned downstream

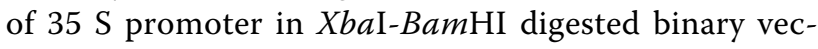
tor pSR3000. Arabidopsis Col-0 plants were transformed by Agrobacterium tumefaciens using the floral dipping method [65]. Transgenic plants were selected on MS medium containing $50 \mu \mathrm{g} \mathrm{mL}^{-1}$ kanamycin.
Protein extracts from T2 generation transgenic plants were analyzed by western analysis using AtNUDT7 polyclonal antibodies.

\section{Potting mix analysis}

Macronutrients and micronutrients measurements in the 12:3:1 potting mix and the commercial Metro-Mix 200 were conducted at the Soil, Water and Forage Analytical Laboratory, Oklahoma State University. Micronutrients were extracted with diethylenetriaminepentaacetic acid solution ( $\mathrm{pH}$ 7.3). Nitrates and ammonium were analyzed on a flow-injection analyzer (Lachat); the nitrates were analyzed using cadmium reduction [66] and the ammonium was analyzed using the salicylate method [67]. Ca, $\mathrm{Mg}, \mathrm{K}, \mathrm{B}, \mathrm{SO} 4, \mathrm{Fe}, \mathrm{Zn}$, and $\mathrm{Cu}$ were analyzed directly by an inductively coupled plasma emission spectrometer (Model Ciros, Spectro).

\section{Stress and chemical treatments}

WT Col-0 plants were grown in MM potting soil and were fertilized on a regular basis. Plants were subjected to biotic and abiotic stresses to examine the changes in AtNUDT7 protein levels.

Bacterial pathogen infection: A suspension $\left(1 \times 10^{5} \mathrm{cfu} /\right.$ $\mathrm{mL}$ in $10 \mathrm{mM} \mathrm{MgCl}_{2}$ ) of virulent Pseudomonas syringae pv. tomato, DC3000 strain, and avirulent strain P. syringae, AvrRpt2 were infiltrated into 4-week-old WT Col-0 plants using a needleless syringe. Leaves were harvested 2, 4, 6, 8 and 24 hours after infiltration. Mock-infiltrated leaf samples $(10 \mathrm{mM} \mathrm{MgCl}$ ) were harvested at the same time as controls. Growth curve analysis of the virulent bacteria was conducted for the plants growing in MM and 12:3:1 mix as described earlier [23].

Acute ozone treatment: WT Ws-0 ecotype plants were grown under short day conditions for 4 weeks and then exposed to $250 \mathrm{~nL} \mathrm{~L}^{-1}$ of ozone for duration of six hours as described earlier [68]. Symptoms on the leaves were evaluated 24 hours after the end of ozone treatment. Leaf samples were harvested 0.5, 1, 2, 3, 4 and 24 hours after the start of treatment.

Wounding: WT Col-0 plants were grown for five weeks in MM under the same conditions described above. Fully expanded leaves were wounded using a sharp blade. About eight hours after treatment, the wounded leaves were harvested for western analysis.

\section{NADH and ADP-ribose treatment}

Five-week-old Col-0 plants were infiltrated using a needleless syringe with $5 \mathrm{mM}$ NADH (Sigma) or $1 \mathrm{mM}$ ADP-ribose (Sigma) dissolved in water. Control plants were infiltrated with distilled water. Leaves from control and NADH or ADP-ribose infiltrated plants were harvested 24 hours after treatment and flash-frozen in liquid nitrogen. 


\section{AtNUDT7 polyclonal antibodies}

Polyclonal anti-NUDT7 antisera were generated in rabbits using full-length recombinant AtNUDT7 as the antigen (Pacific Immunologies Corp.). The generated antisera detected a $33 \mathrm{kDa}$ protein band in total soluble protein extracts from WT Col-0 leaf tissues. This was consistent with the predicted size of AtNUDT7 protein in the Arabidopsis database.

\section{Western analysis}

Total protein was extracted from rosettes using protein extraction buffer $(50 \mathrm{mM}$ Tris $\mathrm{pH}$ 7.5, $150 \mathrm{mM}$ sodium chloride, $50 \mathrm{mM}$ sucrose, $1 \mathrm{mM}$ phenylmethylsulfonyl fluoride, $0.1 \%$ Triton X-100, $1 \mu$ plant protease inhibitor cocktail). Protein concentrations were determined using Bradford reagent (Bio-Rad). Each protein sample $(50 \mu \mathrm{g})$ was resolved on a $15 \%$ SDS-PAGE gel and transferred to a polyvinylidene difluoride membrane by electro blotting (Bio-Rad). The membrane was stained with Coomassie blue (0.2\% Coomassie blue, $50 \%$ methanol, $10 \%$ acetic acid) to check for equal loading and blocked overnight at $4{ }^{\circ} \mathrm{C}$ with Tris-buffered saline, $\mathrm{pH}$ 7.6, containing $0.1 \%$ Tween 20 and $5 \%$ skim milk. Western blot hybridization was conducted as described in the Amersham Biosciences manual. The membrane was incubated for one hour on a shaker at room temperature with a 1:2000 dilution of primary polyclonal antirabbit AtNudt7 antibodies (Pacific Immunology Corp.) in Tris-buffered saline, pH 7.6, containing 0.1\% Tween 20 and $5 \%$ skim milk. Following washes, membranes were incubated for one hour in secondary ECL anti-rabbit IgG horseradish peroxidase-linked whole antibody (Amersham Biosciences) at a dilution of 1:25,000 in TBST. Signal was detected using an ECL kit (Amersham Biosciences).

\section{RNA isolation, GeneChip hybridization, and data analysis}

Total RNA was isolated using the Plant RNeasy kit (Qiagen) from two independent biological replicates of Atnudt7-1 and WT plants growing in 12:3:1 mix. RNA was precipitated using sodium acetate and ethanol. RNA quality and quantity was assessed in a Bioanalyzer (Agilent Technologies). Approximately $10 \mu \mathrm{g}$ of total RNA was used for hybridization, as described earlier [69].

For each Affymetrix array hybridized, the resulting .cel file was exported from GeneChip Operating Software Version 1.4 (Affymetrix) and imported into Robust Multiarray Average [70] for global normalization. The presence/ absence call for each probe set was made using dCHIP software [71]. Gene selections based on an associative ttest [72] were made using Matlab software (MathWorks, Natick, MA). Using this method, the background noise present between replicates and technical noise during hybridization were measured by the residual presented among a group of genes. Only genes whose residuals between the compared sample pairs were significantly higher than the measured noise level were considered differentially expressed. Since the residual was obtained from thousands of genes on the chip, the p-value obtained by this method was corrected for a large sampling size, thus allowing the use of Bonferroni corrections without being overly stringent. The advantage of this methodology is that it takes into consideration technical noise and internal variation between replicates within a sample group and provides a baseline for selecting biologically significant genes [73]. A selection threshold of 2 for transcript ratios (where applicable) and a Bonferroni-corrected p-value threshold of 2.19202E-06 were used to select genes for pathway reconstruction using MAPMAN software [27]. The Bonferroni-corrected $\mathrm{P}=0.05 / \mathrm{N}$, where $\mathrm{N}$ is the number of genes in the comparison $(22,810$ in the experiments reported here). The microarray data have been submitted under the accession number E-MEXP-2711 to the ArrayExpress database.

\section{Protease activity assay}

Azocasein was used as substrate in a general protease assay [68] using total protein extracts from Atnudt7-1 and WT plants. Phenylmethylsulfonyl fluoride $(1 \mathrm{mM})$, an inhibitor of the Ser proteases and the papain family Cys proteases, and leupeptin $(0.1 \mathrm{mM})$, a well-known inhibitor of Cys proteases, were added separately to the homogenate. The assays were replicated three times.

\section{ATP measurement}

About $100 \mathrm{mg}$ of leaf tissue was homogenized with 10 $\mathrm{mM}$ Tris- $\mathrm{HCl}$ buffer ( $\mathrm{pH}$ 7.2). Following centrifugation at $20,000 \mathrm{~g}$ for $10 \mathrm{~min}$ at $4{ }^{\circ} \mathrm{C}$, the supernatant was collected for ATP analysis. ATP was determined using an ATP Bioluminescent Assay kit (Sigma FL-AA). The assays were performed in $15 \mathrm{~mm} \times 60 \mathrm{~mm}$ vials with a luminometer (Lumac/3 M Biocounter M2010A) preset to integrate the amount of light produced over a $10 \mathrm{sec}-$ ond interval without an initial delay. Levels of light produced in WT Col-0 and Atnudt7-1 plant extracts were used to estimate the amount of ATP based on standards. ATP content of the control plants was set to $100 \%$ to determine the relative ATP content.

\section{$\mathrm{NAD}^{+} / \mathrm{NADH}$ measurements}

PN measurements were conducted using $0.2 \mathrm{~g}$ of ground leaf tissue using the enzyme cycling assay $[36,74]$. The analysis was repeated four times, twice from each biological replicate. Standard curves for $\mathrm{NAD}^{+}$and $\mathrm{NADH}$ were generated each time the assay was conducted.

\section{Ascorbate and glutathione measurements}

Ascorbate and glutathione in WT and Atnudt7-1 mutant plants grown in 12:3:1 soil mix and MM were measured as described earlier [68]. To measure ascorbate, about 0.2 
g of leaf tissue was first ground to a fine powder and resuspended in $2 \mathrm{~mL}$ of $2 \%$ metaphosphoric acid and 2 mM EDTA. Following neutralization with $10 \%$ sodium citrate, total ascorbate was analyzed by measuring change in absorbance on a spectrophotometer (PerkinElmer) before and after addition of ascorbate oxidase [75]. To measure glutathione, the neutralized plant extract was

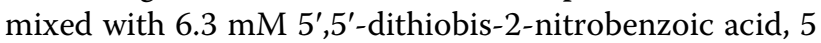
$\mathrm{mM}$ NADPH and one unit of glutathione reductase and then incubated for six minutes at room temperature. Absorbance at $412 \mathrm{~nm}$ was recorded [76]. Two independent measurements each from two biological replications were averaged and used for plotting the graphs.

\section{Real-time PCR analysis}

Total RNA was diluted to $200 \mathrm{ng} / \mu \mathrm{L}$. Approximately 1 $\mu \mathrm{g}$ of this RNA was used for cDNA synthesis by SuperScript reverse transcriptase (Invitrogen) according to the manufacturer's instructions. Primer sequences for all the genes used in RT-PCR analysis are provided in the supporting information (Additional file 4, Table S2). Primers were designed using the Primer Express program (Applied Biosystems) to amplify an 80 base pair fragment. Real-time RT-PCR was performed using the SYBR Green kit (Fermentas) as described earlier [77]. Samples were run and analyzed using an ABI PRISM 5700 (Applied Biosystems) according to the manufacturer's instructions. The experiment was repeated twice using different cDNA preparations and the average delta delta $\mathrm{Ct}$ values were plotted with standard deviation.

\section{Statistical analysis}

One-way ANOVA was performed to study the differences in $\mathrm{NAD}^{+}, \mathrm{NADH}, \mathrm{GSH}, \mathrm{AsA}$ and DHA levels in Atnudt7-1 mutant and WT Col-0 plants grown in two different potting mixes (MM and 12:3:1 mix). Tukey's studentized range test (95\% confidence level) was performed using Statistical Analysis Software (SAS Enterprise Group 4.0, SAS Institute). Microsoft Excel was used for calculating statistical significance of real-time PCR data between two treatments or samples.

\section{Additional material}

Additional file 1: Fig. S1: Analysis of bacterial growth and pyridine nucleotide levels in $P_{35 s}$ : AtNUDT7 transgenic plants.

Additional file 2: Table S1: List of genes that are differentially expressed in Atnudt7-1 mutant compared with WT plants grown in the 12:3:1 potting mix.

Additional file 3: Fig. S2: MAPMAN view of receptor-like kinases altered in the Atnudt7-1 mutant.

Additional file 4: Table S2: List of primers used for real-time PCR analysis.

\section{Acknowledgements}

This work was partially supported by USDA (NRI 2007-02635), NSF EPSCoR (EPS 0814361) and Oklahoma Agricultural Experiment Station (Project no. 2528). Authors thank Stacy Allen, Samuel Roberts Noble Foundation, for assistance with the Affymetrix Genechip hybridizations. The authors thank the OSU Recombinant DNA and Proteomics Facility for the real-time PCR equipment.

\section{Author details}

${ }^{1} 246$ Noble Research Center, Department of Biochemistry and Molecular Biology, Oklahoma State University, Stillwater, Oklahoma, USA. ${ }^{2}$ The Samuel Roberts Noble Foundation Inc., Plant Biology Division, Ardmore, Oklahoma, USA.

\section{Authors' contributions}

$\mathrm{NJ}$ conducted all the biochemical assays, phenotype analysis, real-time PCR and drafted the manuscript. AP conducted the microarray experiments and western analysis. YT conducted microarray data analysis. RM was responsible for overseeing the experiments, data verification and writing the manuscript. All authors have read and approved the final manuscript.

Received: 5 February 2010 Accepted: 12 August 2010

Published: 12 August 2010

\section{References}

1. Berger $\mathrm{F}$, Ramirez-Hernandez $\mathrm{MH}$, Ziegler $\mathrm{M}$ : The new life of a centenarian: signalling functions of NAD(P). Trends in Biochemical Sciences 2004, 29:111-118.

2. Mahalingam R, Jambunathan N, Penaganti A: Pyridine nucleotide homeostasis in Plant Development and Stress. International Journal of Plant Developmental Biology 2007, 1:194-201.

3. Hunt L, Gray JE: The relationship between pyridine nucleotides and seed dormancy. New Phytol 2009, 181:62-70.

4. Bonzon M, Simon P, Greppin H, Wagner E: Pyridine-nucleotides and redox charge evolution during the induction of flowering in spinach leaves. Planta 1983, 159:254-260

5. Yamamoto Y: Pyridine nucleotide content in higher plant: Effect of age of tissue. Plant Physiology 1963, 38:45-54.

6. Ge X, Li GJ, Wang SB, Zhu H, Zhu T, Wang X, Xia Y: AtNUDT7, a negative regulator of basal immunity in Arabidopsis, modulates two distinct defense response pathways and is involved in maintaining redox homeostasis. Plant Physiol 2007, 145:204-215.

7. Kuraishi S, Arai N, Ushijima T, Tazaki T: Oxidized and reduced nicotinamide adenine dinucleotide phosphate levels of plants hardened and unhardened against chilling injury. Plant Physiology 1968, 43:238-242.

8. Robertson D, Davies DR, Gerrish C, Jupe SC, Bolwell GP: Rapid changes in oxidative metabolism as a consequence of elicitor treatment of suspension-cultured cells of French bean (Phaseolus vulgaris L.). Plant Mol Biol 1995, 27:59-67.

9. Zagdanska B: Effect of water-stress upon the pyridine-nucleotide pool in wheat leaves. Journal of Plant Physiology 1989, 134:320-326.

10. Zhang X, Mou Z: Extracellular pyridine nucleotides induce PR gene expression and disease resistance in Arabidopsis. Plant J 2009, 57:302-312.

11. Blander $G$, Guarente L: The Sir2 family of protein deacetylases. Annual Review of Biochemistry 2004, 73:417-435.

12. Kim SJ, Jeong DH, An GH, Kim SR: Characterization of a droughtresponsive gene, OsTPS1, identified by the T-DNA gene-trap system in rice. Journal of Plant Biology 2005, 48:371-379.

13. Zheng QC, Li ZS, Sun M, Zhang Y, Sun CC: Homology modeling and substrate binding study of Nudix hydrolase $\mathrm{Ndx} 1$ from Thermos thermophilus HB8. Biochemical and Biophysical Research Communications 2005, 333:881-887.

14. Zhang Q, Piston DW, Goodman RH: Regulation of corepressor function by nuclear NADH. Science 2002, 295:1895-1897.

15. Bessman MJ, Frick DN, O'Handley SF: The MutT proteins or "Nudix" hydrolases, a family of versatile, widely distributed, "housecleaning" enzymes. J Biol Chem 1996, 271:25059-25062.

16. Kraszewska E: The plant Nudix hydrolase family. Acta Biochim Pol 2008 , 55:663-671. 
17. Ogawa T, Ueda Y, Yoshimura K, Shigeoka S: Comprehensive analysis of cytosolic nudix hydrolases in Arabidopsis thaliana. J Biol Chem 2005, 280:25277-25283.

18. Dobrzanska M, Szurmak B, Wyslouch-Cieszynska A, Kraszewska E: Cloning and characterization of the first member of the Nudix family from Arabidopsis thaliana. Journal of Biological Chemistry 2002, 277:50482-50486.

19. Klaus SM, Wegkamp A, Sybesma W, Hugenholtz J, Gregory JF, Hanson AD: A nudix enzyme removes pyrophosphate from dihydroneopterin triphosphate in the folate synthesis pathway of bacteria and plants. $J$ Biol Chem 2005, 280:5274-5280

20. Ogawa T, Ishikawa K, Harada K, Fukusaki E, Yoshimura K, Shigeoka S: Overexpression of an ADP-ribose pyrophosphatase, AtNUDX2, confers enhanced tolerance to oxidative stress in Arabidopsis plants. Plant J 2009, 57:289-301.

21. Adams-Phillips L, Wan J, Tan X, Dunning FM, Meyers BC, Michelmore RW, Bent AF: Discovery of ADP-ribosylation and other plant defense pathway elements through expression profiling of four different ArabidopsisPseudomonas R-avr interactions. Mol Plant Microbe Interact 2008, 21:646-657.

22. Ishikawa K, Ogawa T, Hirosue E, Nakayama Y, Harada K, Fukusaki E, Yoshimura K, Shigeoka S: Modulation of the poly(ADP-ribosyl)ation reaction via the Arabidopsis ADP-ribose/NADH pyrophosphohydrolase, AtNUDX7, is involved in the response to oxidative stress. Plant Physiol 2009, 151:741-754

23. Jambunathan N, Mahalingam R: Analysis of Arabidopsis Growth Factor Gene 1 (GFG1) encoding a nudix hydrolase during oxidative signaling. Planta 2006, 224:1-11.

24. Olejnik K, Kraszewska E: Cloning and characterization of an Arabidopsis thaliana Nudix hydrolase homologous to the mammalian GFG protein. Biochimica Et Biophysica Acta-Proteins and Proteomics 2005, 1752:133-141.

25. Olejnik K, Plochocka D, Grynberg M, Goch G, Gruszecki WI, Basinska T, Kraszewska E: Mutational analysis of the AtNUDT7 Nudix hydrolase from Arabidopsis thaliana reveals residues required for protein quaternary structure formation and activity. Acta Biochim Pol 2009, 56:291-300.

26. Bartsch M, Gobbato E, Bednarek P, Debey S, Schultze JL, Bautor J, Parker JE: Salicylic acid-independent ENHANCED DISEASE SUSCEPTIBILITY1 signaling in Arabidopsis immunity and cell death is regulated by the monooxygenase FMO1 and the nudix hydrolase NUDT7. Plant Cell 2006, 18:1038-1051

27. Thimm O, Blasing O, Gibon Y, Nagel A, Meyer S, Kruger P, Selbig J, Muller LA, Rhee SY, Stitt M: MAPMAN: a user-driven tool to display genomics data sets onto diagrams of metabolic pathways and other biological processes. Plant J 2004, 37:914-939.

28. Lin SJ, Guarente L: Nicotinamide adenine dinucleotide, a metabolic regulator of transcription, longevity and disease. Curr Opin Cell Biol 2003, 15:241-246.

29. Wildermuth MC, Dewdney J, Wu G, Ausubel FM: Isochorismate synthase is required to synthesize salicylic acid for plant defense. Nature 2001, 414:562-565.

30. Alonso M, Hidalgo J, Hendricks L, Velasco A: Degradation of aggrecan precursors within a specialized subcompartment of the chicken chondrocyte endoplasmic reticulum. Biochemical Journal 1996, 316:487-495

31. Overmyer K, Brosche M, Kangasjarvi J: Reactive oxygen species and hormonal control of cell death. Trends in Plant Science 2003, 8:335-342.

32. Hara $Y$, Wakamori M, Ishii M, Maeno E, Nishida M, Yoshida T, Yamada $H$, Shimizu S, Mori E, Kudoh J, et al: LTRPC2 Ca2+-permeable channel activated by changes in redox status confers susceptibility to cell death. Mol Cell 2002, 9:163-173.

33. Perraud AL, Fleig A, Dunn CA, Bagley LA, Launay P, Schmitz C, Stokes AJ, Zhu Q, Bessman MJ, Penner R, et al: ADP-ribose gating of the calciumpermeable LTRPC2 channel revealed by Nudix motif homology. Nature 2001, 411:595-599.

34. Dutilleul C, Lelarge C, Prioul JL, De Paepe R, Foyer CH, Noctor G: Mitochondria-driven changes in leaf NAD status exert a crucial influence on the control of nitrate assimilation and the integration of carbon and nitrogen metabolism. Plant Physiol 2005, 139:64-78.

35. Dutilleul C, Garmier M, Noctor G, Mathieu C, Chetrit P, Foyer CH, de Paepe R: Leaf mitochondria modulate whole cell redox homeostasis, set antioxidant capacity, and determine stress resistance through altered signaling and diurnal regulation. Plant Cell 2003, 15:1212-1226.
36. Shen W, Wei Y, Dauk M, Tan Y, Taylor DC, Selvaraj G, Zou J: Involvement of a glycerol-3-phosphate dehydrogenase in modulating the NADH/NAD+ ratio provides evidence of a mitochondrial glycerol-3-phosphate shuttle in Arabidopsis. Plant Cell 2006, 18:422-441.

37. Shen W, Wei Y, Dauk M, Zheng Z, Zou J: Identification of a mitochondrial glycerol-3-phosphate dehydrogenase from Arabidopsis thaliana: evidence for a mitochondrial glycerol-3-phosphate shuttle in plants. FEBS Lett 2003, 536:92-96.

38. Millar AH, Hill SA, Leaver CJ: Plant mitochondrial 2-oxoglutarate dehydrogenase complex: purification and characterization in potato. Biochem J 1999, 343:327-334.

39. Bowling SA, Guo A, Cao H, Gordon AS, Klessig DF, Dong XI: A mutation in Arabidopsis that leads to constitutive expression of Systemic AcquiredResistance. Plant Cell 1994, 6:1845-1857.

40. Draper J: Salicylate, superoxide synthesis and cell suicide in plant defense. Trends in Plant Science 1997, 2:162-165.

41. McDowell JM, Dangl JL: Signal transduction in the plant immune response. Trends Biochem Sci 2000, 25:79-82.

42. Ryals J, Lawton KA, Delaney TP, Friedrich L, Kessmann H, Neuenschwander U, Uknes S, Vernooij B, Weymann K: Signal transduction in systemic acquired resistance. Proc Natl Acad Sci USA 1995, 92:4202-4205.

43. Bi $Y M$, Kenton $P$, Mur L, Darby R, Draper J: Hydrogen peroxide does not function downstream of salicylic acid in the induction of PR protein expression. Plant J 1995, 8:235-245.

44. Leon J, Shulaev V, Yalpani N, Lawton MA, Raskin I: Benzoic acid 2hydroxylase, a soluble oxygenase from tobacco, catalyzes salicylic acid biosynthesis. Proc Natl Acad Sci USA 1995, 92:10413-10417.

45. Rao MV, Paliyath $C$, Ormrod DP, Murr DP, Watkins CB: Influence of salicylic acid on $\mathrm{H}_{2} \mathrm{O} 2$ production, oxidative stress, and $\mathrm{H}_{2} \mathrm{O}_{2}$-metabolizing enzymes - Salicylic acid-mediated oxidative damage requires $\mathrm{H}_{2} \mathrm{O}_{2}$. Plant Physiology 1997, 115:137-149.

46. Mateo A, Funck D, Muhlenbock P, Kular B, Mullineaux PM, Karpinski S: Controlled levels of salicylic acid are required for optimal photosynthesis and redox homeostasis. J Exp Bot 2006, 57:1795-1807.

47. Creissen G, Firmin J, Fryer M, Kular B, Leyland N, Reynolds H, Pastori G, Wellburn F, Baker N, Wellburn A, et al: Elevated glutathione biosynthetic capacity in the chloroplasts of transgenic tobacco plants paradoxically causes increased oxidative stress. Plant Cell 1999, 11:1277-1292.

48. Foyer $\mathrm{CH}$, Noctor G: Oxidant and antioxidant signalling in plants: a reevaluation of the concept of oxidative stress in a physiological context. Plant Cell and Environment 2005, 28:1056-1071.

49. Foyer $\mathrm{CH}$, Noctor $\mathrm{G}$ : Redox regulation in photosynthetic organisms: Signaling, acclimation, and practical implications. Antioxid Redox Signal 2009, 11:861-905.

50. Hoeberichts FA, Woltering EJ: Multiple mediators of plant programmed cell death: interplay of conserved cell death mechanisms and plantspecific regulators. Bioessays 2003, 25:47-57.

51. Dietz KJ: Redox signal integration: from stimulus to networks and genes. Physiol Plant 2008, 133:459-468.

52. Noctor G, Queval G, Gakiere B: NAD(P) synthesis and pyridine nucleotide cycling in plants and their potential importance in stress conditions. Journal of Experimental Botany 2006, 57:1603-1620.

53. Noctor G, De Paepe R, Foyer CH: Mitochondrial redox biology and homeostasis in plants. Trends Plant Sci 2007, 12:125-134.

54. Ziegler M: New functions of a long-known molecule: Emerging roles of NAD in cellular signaling. Eur J Biochem 2000, 267:1550-1564.

55. Alano CC, Swanson RA: Players in the PARP-1 cell-death pathway: JNK1 joins the cast. Trends Biochem Sci 2006, 31:309-311.

56. Virag L, Szabo C: The therapeutic potential of poly(ADP-ribose) polymerase inhibitors. Pharmacol Rev 2002, 54:375-429.

57. Ying WH, Garnier P, Swanson RA: NAD(+) repletion prevents PARP-1induced glycolytic blockade and cell death in cultured mouse astrocytes. Biochemical and Biophysical Research Communications 2003, 308:809-813.

58. Rutter J, Reick M, Wu LC, McKnight SL: Regulation of clock and NPAS2 DNA binding by the redox state of NAD cofactors. Science 2001, 293:510-514.

59. Mou Z, Fan WH, Dong XN: Inducers of plant systemic acquired resistance regulate NPR1 function through redox changes. Cell 2003, 113:935-944. 
60. Tada Y, Spoel SH, Pajerowska-Mukhtar K, Mou Z, Song J, Wang C, Zuo J, Dong X: Plant immunity requires conformational charges of NPR1 via S-nitrosylation and thioredoxins. Science 2008, 321:952-956.

61. Yasuda M, Ishikawa A, Jikumaru Y, Seki M, Umezawa T, Asami T, MaruyamaNakashita A, Kudo T, Shinozaki K, Yoshida S, et al: Antagonistic interaction between systemic acquired resistance and the abscisic acid-mediated abiotic stress response in Arabidopsis. Plant Cell 2008, 20:1678-1692.

62. Mauch-Mani B, Mauch F: The role of abscisic acid in plant-pathogen interactions. Curr Opin Plant Biol 2005, 8:409-414.

63. Mohr PG, Cahill DM: Suppression by ABA of salicylic acid and lignin accumulation and the expression of multiple genes, in Arabidopsis infected with Pseudomonas syringae pv. tomato. Funct Integr Genomics 2007, 7:181-191.

64. Torres MA, Dangl JL: Functions of the respiratory burst oxidase in biotic interactions, abiotic stress and development. Current Opinion in Plant Biology 2005, 8:397-403.

65. Clough SJ, Bent AF: Floral dip: a simplified method for Agrobacteriummediated transformation of Arabidopsis thaliana. Plant J 1998, 16:735-743.

66. Wood RD, Chaney CH, Waddill DG, Garrison GW: Effect of adding nitrate or nitrite to drinking water on the utilization of carotene by growing swine. J Anim Sci 1967, 26:510-513.

67. Krom MD, Berner RA: The diffusion coefficients of sulfate, ammonium, and phosphate ions in anoxic marine sediments. Limnol Oceanogr 1980, 25:327-337.

68. Mahalingam R, Jambunathan N, Gunjan SK, Faustin E, Weng H, Ayoubi P: Analysis of oxidative signalling induced by ozone in Arabidopsis thaliana. Plant Cell and Environment 2006, 29:1357-1371.

69. Teaster ND, Motes CM, Tang Y, Wiant WC, Cotter MQ, Wang YS, Kilaru A, Venables BJ, Hasenstein KH, Gonzalez G, et al: N-Acylethanolamine metabolism interacts with abscisic acid signaling in Arabidopsis thaliana seedlings. Plant Cell 2007, 19:2454-2469.

70. Irizarry RA, Wu Z, Jaffee HA: Comparison of Affymetrix GeneChip expression measures. Bioinformatics 2006, 22:789-794.

71. Li C, Wong WH: Model-based analysis of oligonucleotide arrays: expression index computation and outlier detection. Proc Natl Acad Sci USA 2001, 98:31-36.

72. Dozmorov I, Centola M: An associative analysis of gene expression array data. Bioinformatics 2003, 19:204-211.

73. Benedito VA, Torres-Jerez I, Murray JD, Andriankaja A, Allen S, Kakar K, Wandrey M, Verdier J, Zuber H, Ott T, et al: A gene expression atlas of the model legume Medicago truncatula. Plant J 2008, 55:504-513.

74. Matsumara H, Miyachi S: Cycling assay for nicotinamide adenine dinucleotides. Methods in Enzymology 1980, 69:465-470.

75. Rao MV, Hale BA, Ormrod DP: Amelioration of ozone-induced oxidative damage in Wheat plants grown under high carbon dioxide (Role of antioxidant enzymes). Plant Physiol 1995, 109:421-432.

76. Griffith OW: Determination of glutathione and glutathione disulfide using glutathione reductase and 2-vinylpyridine. Anal Biochem 1980 106:207-212.

77. Puckette MC, Tang Y, Mahalingam R: Transcriptomic changes induced by acute ozone in resistant and sensitive Medicago truncatula accessions. BMC Plant Biol 2008, 8:46.

\section{doi:10.1186/1471-2229-10-173}

Cite this article as: Jambunathan et al: Modulation of redox homeostasis under suboptimal conditions by Arabidopsis nudix hydrolase 7. BMC Plant Biology 2010 10:173.

\section{Submit your next manuscript to BioMed Central and take full advantage of:}

- Convenient online submission

- Thorough peer review

- No space constraints or color figure charges

- Immediate publication on acceptance

- Inclusion in PubMed, CAS, Scopus and Google Scholar

- Research which is freely available for redistribution

Submit your manuscript at www.biomedcentral.com/submit 